\title{
Nicotinic Receptors Mediate Changes in Spinal Motoneuron Development and Axonal Pathfinding in Embryonic Zebrafish Exposed to Nicotine
}

\author{
Kurt R. Svoboda, ${ }^{1,2}$ Sukumar Vijayaraghavan, ${ }^{2}$ and Robert L. Tanguay ${ }^{3}$ \\ ${ }^{1}$ Department of Biological Sciences, Louisiana State University, Baton Rouge, Louisiana 70803, 2School of Medicine, \\ Department of Physiology and Biophysics, and ${ }^{3}$ School of Pharmacy, Department of Pharmaceutical Sciences, University \\ of Colorado Health Sciences Center, Denver, Colorado 80262
}

\begin{abstract}
We show that transient exposure of embryonic zebrafish to nicotine delays the development of secondary spinal motoneurons. Furthermore, there is a long-lasting alteration in axonal pathfinding in secondary motoneurons that is not ameliorated by drug withdrawal. These effects of nicotine were reversed by mammalian nicotinic receptor antagonists. Coupled with these changes is a long-term alteration in swimming behavior. Our results show that transient embryonic exposure to nicotine
\end{abstract}

leads to long-lasting effects on the vertebrate nervous system. These results also demonstrate that the zebrafish is a useful model to examine the effects of nicotine specifically, and drugs of abuse in general, on the development of the CNS in vertebrates.

Key words: nicotine; zebrafish; motoneurons; development; zn5; znS5
Nicotine, a drug of abuse, has been purported to have many effects on the developing nervous system. A significant number of women smoke during pregnancy. Exposure of the developing fetus to nicotine from the maternal serum has been linked to a number of abnormalities, including spontaneous abortions, low birth weight, sudden infant death (DiFranza and Lew, 1995), and significant cognitive, intellectual, and behavioral impairments in offspring (Sexton et al., 1990; Olds et al., 1994).

It is accepted that the physiological responses to nicotine are mediated via the activation of neuronal nicotinic acetylcholine receptors (nAChRs). Over the past two decades, a number of genes encoding subunits of nAChRs have been cloned (for review, see Role and Berg, 1996). The nAChRs are composed of 12 gene products $(\alpha 2-\alpha 10$ and $\beta 2-\beta 4)$, which are organized into two pharmacologically distinguishable classes of receptors. The first class consists of the nAChR $\alpha 7-\alpha 9$ gene products, whose function is blocked by nanomolar levels of the snake venom toxin $\alpha$-bungarotoxin ( $\alpha \mathrm{Bgt}$ ). The $\alpha 7$-containing $\alpha \mathrm{Bgt}$ receptor is the most abundant and is thought to be functionally homopentameric; it is present both in the CNS and in the peripheral nervous system (PNS) (Role and Berg, 1996). nAChRs that contain the $\alpha 7$ subunit are also blocked by nanomolar concentrations of methyllycaconitine (MLA) (Ward et al., 1990). The second class of $\mathrm{nAChRs}$ consists of heteromeric combinations of the various $\alpha$

Received April 17, 2002; revised Oct. 1, 2002; accepted Oct. 1, 2002.

This work was supported by National Institutes of Health (NIH) Grant F32MH12748 (K.R.S.), NIH/National Institute on Alcohol Abuse and Alcoholism Grant AA12783 (R.L.T.), NIH/National Institute on Drug Abuse Grant DA10266 (S.V.), NIH Grant NS38937 (A.B.R.), and Colorado Tobacco Research Program Grant 2R-019 (R.L.T.).We thank Amanda Laughlin for excellent technical assistance, Steve Fadul for microscopic imaging assistance and help with the generation of the Z-series projections, Drs. Shin-ichi Higashijima and Hitoshi Okamoto for providing the islet-1-GFP transgenic fish essential for these studies, and Dr. Angeles B. Ribera for the use of microscope and imaging systems.

Correspondence should be addressed to Dr. Robert L. Tanguay, University of Colorado Health Sciences Center, Department of Pharmaceutical Sciences, Box C-238 4200 East Ninth Avenue, Denver, CO 80262. E-mail: robert.tanguay@uchsc.edu. Copyright (C) 2002 Society for Neuroscience $0270-6474 / 02 / 2210731-11 \$ 15.00 / 0$ and $\beta$ subunits, and their function is not blocked by $\alpha$ Bgt. Pharmacological tools are available that distinguish between the heteromeric subtypes of nAChRs (Colquhoun and Patrick, 1997). These include dihydro- $\beta$-erythroidine $(\mathrm{DH} \beta \mathrm{E})$, an agent selective for the $\alpha 4 \beta 2$ subtype, and various conotoxins that selectively target different subtypes of nAChRs (for review, see McIntosh et al., 1999).

The presence of both acetylcholine (ACh) and nAChRs during embryogenesis suggests that nAChRs play a significant role during development. Choline acetyltransferase, the enzyme required for ACh synthesis, has been detected as early as the neural plate stages in the presumptive crest (Smith et al., 1979). Transcripts for $\mathrm{nAChR}$ subunits have been detected as early as embryonic day 2 in the mouse (Zoli et al., 1995). Significant levels of acetylcholinesterase have been shown in the developing zebrafish nervous system (Hanneman and Westerfield, 1989). In the developing rat CNS, prenatal exposure to nicotine leads to impairments in the cholinergic, (Navarro et al., 1989), adrenergic (Navarro et al., 1990), dopaminergic, and serotonergic systems (Muneoka et al., 1997). Exposing hippocampal progenitor cells to low levels of nicotine causes rapid and selective apoptotic cell death of undifferentiated progenitor cells (Berger et al., 1998). In nonmammalian vertebrates, nAChRs have been implicated in neurite outgrowth in chick ciliary ganglion neurons (Pugh and Berg, 1994) and in Xenopus spinal neurons (Zheng et al., 1994). In the developing chick spinal cord, nAChRs are involved in the regulation of motoneuron survival (Hory-Lee and Frank, 1995; Oppenheim et al., 2000). These studies suggest strongly that nAChRs have effects on neuronal development and axonal pathfinding in the CNS and the PNS.

An ideal model system for examining mechanisms underlying nicotinic effects on neuronal development should have the following characteristics: (1) responsive to nicotine exposure, (2) a relatively simple nervous system, (3) a short developmental period, which allows examination of temporally spaced events between embryogenesis and adulthood, and (4) a system amenable 
to experimental manipulations. The well established zebrafish model possesses all of these characteristics.

We used a transgenic zebrafish that expresses green fluorescent protein (GFP) in a subtype of spinal secondary motoneuron (Higashijima et al., 2000) to investigate the effects of nicotine on motoneuron development. A fragment of the islet-1 promoter constitutively drives the GFP expression in these embryos (Higashijima et al., 2000). This transgenic line has been used recently to characterize the axonal branching patterns of motoneurons and also to characterize neuromuscular development in embryonic and larval zebrafish (Higashijima et al., 2000; Ono et al., 2001; Segawa et al., 2001). It is known that GFP expression is confined to a subclass of secondary motoneurons (Higashijima et al., 2000) in embryos older than 3 d postfertilization. During early developmental stages, some spinal cord interneurons express GFP; however, they are easily distinguished from secondary motoneurons because they lie dorsal to the primary and secondary motoneurons (Kuwada et al., 1990; Hale et al., 2001). Secondary motoneurons that express GFP in the islet-1 transgenic embryo are identified according to their ventral positions in spinal cord and by the fact that their axons can be easily detected innervating either the ventral or dorsal musculature of the embryo.

In this study, we assessed the impact of nicotine exposure on the developing zebrafish embryo. We observed that nicotine impairs the touch/escape response as well as the swimming behavior of embryos. We also demonstrate that nicotine delays differentiation and alters axonal pathfinding in secondary motoneurons.

\section{MATERIALS AND METHODS}

Embryo maintenance and drug exposure. The islet-1 transgenic line was kindly provided by Dr. Shin-ici Higashijima from the State University of New York (Stony Brook, NY). The results reported here did not depend on the genetic background (heterozygous or homozygous islet-1 expression). All of the results reported are from embryos homozygous for islet-1 expression. We also used four different wild-type strains in this study (AB, WIK, Tübingen, and pet store; the latter are fish from a local pet store); similar behavioral and anatomical results were obtained with all four strains. Adults and embryos were housed at $28^{\circ} \mathrm{C}$ in a fish facility maintained in the Center for Animal Laboratory Care at the University of Colorado Health Sciences Center. Embryos were developmentally staged according to methods described previously (Kimmel et al., 1995). For all of the described experiments, 19-21 hr postfertilization (hpf) embryos were manually dechorionated and transferred at $22 \mathrm{hpf}$ to embryo medium containing $0.002 \%$ 1-phenyl-2 thiourea (PTU), which inhibits pigment formation (Westerfield, 1995). For nicotine exposures, nicotine $(0-33 \mu \mathrm{M})$ was added directly to PTU-containing embryo medium. In experiments in which nicotinic receptor antagonists were used, the antagonist was applied $2 \mathrm{hr}$ earlier than the nicotine. MLA was used at concentrations of $100 \mathrm{nM}$ and $2 \mu \mathrm{M}$, respectively. DH $\beta \mathrm{E}$ was used at a concentration of $20 \mu \mathrm{M}$. Embryos received fresh embryo media (with nicotine and/or the appropriate antagonists, depending on the experimental group) every $24 \mathrm{hr}$.

Behavior. Embryos were placed in $100 \mathrm{~mm}$ Petri dishes and videotaped using a video camera mounted on a dissecting microscope. Escape and swimming behaviors were initiated by delivering a tactile stimulus to the tail bud of the embryos. An estimate of embryonic/larvae swim velocity was determined by calculating how long it took an embryo to swim completely out of the field of view of the video camera. This was determined by counting the number of frames after stimulation that was required for the embryo to completely swim out of the field of view. We view this as a good estimate of velocity, because the resolution of this procedure is $\pm 33 \mathrm{msec}$ when taking into account the capture rate of a standard video camera, which is 30 frames per second.

Gross morphology. Images of embryos $<66$ hpf were obtained using an RT Spot digital camera (Roper Scientific, Trenton, NJ) mounted on a Nikon (Tokyo, Japan) TE200 inverted microscope with a $4 \times$ objective. Whole embryos older than $66 \mathrm{hpf}$ were too large to be viewed on the inverted microscope and were imaged using a Princeton Instruments (Trenton, NJ) digital camera mounted on a Nikon dissecting microscope.

Morphological analysis of each embryo was performed using the software package Image Pro Plus 4 (Media Cybernetics, Silver Spring, MD). The images of each individual embryo were magnified to allow for easy visualization of the tail bud and the head of the embryo. For each embryo, a straight line was drawn from the tip of the olfactory placode region to the tip of the tail bud. The lengths for each of these lines were measured in pixels and then calibrated and converted post hoc to provide lengths in micrometers. Levels of statistical significance were assessed by an unpaired two-tailed Students $t$ test; $p$ values of $<0.05$ were considered to indicate statistical significance (SigmaStat software, Chicago, IL).

Immunocytochemistry. Embryos were fixed overnight at $4^{\circ} \mathrm{C}$ in $4 \%$ paraformaldehyde in PBS containing $0.1 \%$ Tween 20 (PBST). Fixed embryos were washed and stored in PBST at $4^{\circ} \mathrm{C}$. Tail clippings were used to distinguish unexposed controls from nicotine-exposed embryos. This allowed embryos from these two groups to be processed in the same reaction vial to ensure procedural consistency. Details of the immunocytochemical protocol we used have been published previously (Svoboda et al., 2001). The monoclonal antibodies zn5 and znS5 (Institute of Neuroscience, University of Oregon, Eugene, OR) were used at a dilution of 1:500 and 1:1000, respectively. A fluorescent secondary antibody (Alexa 546; Molecular Probes, Eugene, OR) was used at a 1:1000 dilution to reveal primary antibody labeling.

Visualization of GFP expression and antibody labeling. Live islet-1 embryos expressing GFP were used in this study. The embryos were placed in a single drop of embryo medium on 1-mm-thick slides, oriented on the microscope stage, and viewed with an Nikon Eclipse TE200 inverted microscope with a $20 \times$ objective $(0.45$ numerical aperture $)$ equipped with a GFP filter cube. Embryos were first viewed in a bright field to get a clear view of the otic vesicle. When a crisp view of the otic vesicle was achieved, the region of rostral spinal cord followed by caudal spinal cord was imaged under epifluorescence with the GFP filter set.

Images of live embryos were acquired using an RT Spot digital camera. For each experiment, the exposure setting required to get a nonsaturating image of GFP expression in control embryos was determined. For any particular experiment, when the control images were acquired, images of the embryos exposed to nicotine were acquired using the same exposure times as controls. In some instances, the exposure time used for the controls was insufficient to detect GFP signals in treated embryos; the exposure settings were then adjusted. In no case was the exposure time for the nicotine-treated islet-1 transgenic embryos shorter than those used to acquire images of control embryos. Exposure times are given in the figure legends. In some instances, images of live embryos that expressed GFP were collected on an Olympus inverted microscope (Olympus Optical, Tokyo, Japan), coupled with a PhotoMetrics (Huntington, Beach, CA) PXL camera with a Kodak KAF1400 chip (Eastman Kodak, Rochester, NY). For these experiments, live embryos were embedded laterally in $1.2 \%$ low-melting-point agarose on coverslips and then oriented to get a view of the rostral spinal cord. Sixty-four serial images were collected at $0.50 \mu \mathrm{m}$ intervals to allow for the sampling of a $32-\mu \mathrm{m}$-thick section of spinal cord. The exposure time for the acquisition of each individual image was $1 \mathrm{sec}$. The individual images comprising each $\mathrm{z}$-series were then compressed and projected as a single image with the aid of Deltavision deconvolution software (Applied Precision, Seattle, WA).

Embryos that had been processed for zn5 and znS5 immunoreactivity were mounted laterally, viewed on an Nikon Eclipse TE300 inverted microscope with a $20 \times$ objective $(0.45$ numerical aperture), and photographed using a Princeton Instruments MicroMax digital camera. As was the case for the imaging of live embryos, exposure times were constant for control and treated embryos. All acquired images, excluding the $\mathrm{Z}$-series projections, were digitally processed with the aid of Adobe Photoshop 5.5 (Adobe Systems, San Jose, CA). Using the invert function, the GFP or rhodamine signals were converted to a black-and-white image. All analyses were performed on inverted images.

Analysis of motoneuron innervation of the ventral and dorsal myotomes. The expression of GFP in secondary motoneuron axons innervating ventral myotomes was used as an indicator of motoneuron development in transgenic embryos. Images of embryos containing GFP were magnified until all of the myotome segments were easily visible. It was then empirically determined whether GFP expression was visible in the nerves exiting the ventral root. We were not concerned with the extent of GFP expression in a given ventral root. The data are reported as the number of segments that had GFP-expressing nerve roots versus the total number 


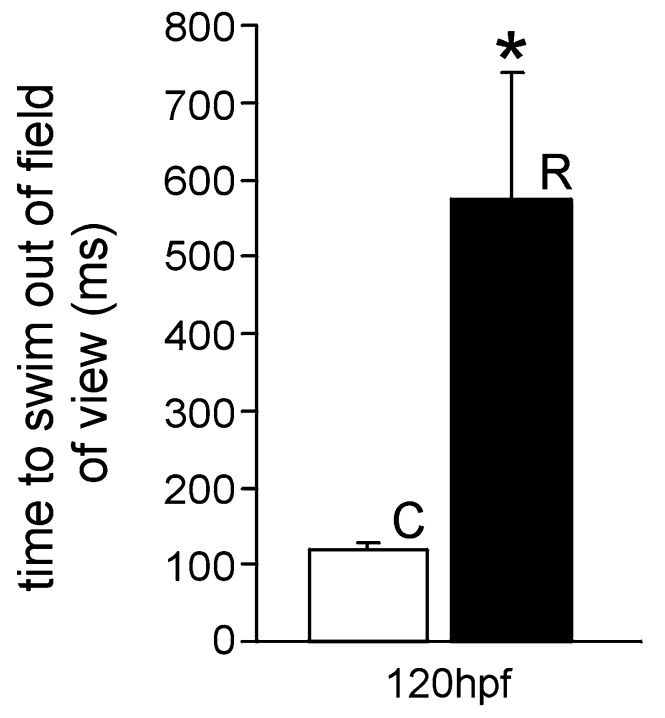

Figure 1. Behavioral consequences of embryos exposed to nicotine. The 120 hpf wild-type control embryos escape and swim completely from the field of view faster than $120 \mathrm{hpf}$ embryos that were rescued from nicotine at $66 \mathrm{hpf}$ [control $(C), n=6,118.8 \pm 8.03 \mathrm{msec}$; rescued $(R), n=12$, $573.4 \pm 165.5 \mathrm{msec}] .{ }^{*} p<0.01$.

of segments analyzed. We counted a minimum of six to seven segments per embryo in both rostral and caudal spinal cord (segments 2-7, rostral analysis, and a six-segment region over the yolk sac extension for caudal analysis). The results obtained were consistent regardless of the region of spinal cord analyzed.

This same analysis protocol was performed for embryos processed for zn5 immunocytochemistry. However, we focused our attention on the axons that innervated the dorsal instead of the ventral myotomes. For these analyses, we directed our efforts to the caudal region of the spinal cord spanning the yolk sac extension. This region was reliably imaged after the embryos were mounted under a coverslip.

\section{RESULTS}

Zebrafish embryos can perceive tactile stimulation beginning at 27 hpf; this is characterized by a bend of the musculature away from the stimulus (Granato and Nusslein-Volhard, 1996; Ribera and Nusslein-Volhard, 1998; Saint-Amant and Drapeau, 1998). By 36-42 hpf, embryos swim vigorously in response to tactile stimulation. Embryos exposed to $33 \mu \mathrm{M}$ nicotine are functionally paralyzed at $42 \mathrm{hpf}$. They respond to tactile stimulation with a bend of the musculature, but they fail to swim. This is in contrast to control 42 hpf embryos, which swim vigorously with tactile stimulation. When continuously exposed to $33 \mu \mathrm{M}$ nicotine, embryos remained functionally paralyzed as late as $120 \mathrm{hpf}$, the latest time point measured. When embryos were exposed to nicotine from 22 to 66 hpf and then returned to nicotine-free embryo media (rescued), there was a partial recovery of behavior at 120 and $168 \mathrm{hpf}$. Specifically, embryos responded with an escape bend followed by high-frequency, alternating bends of the trunk. Although the rescued embryos can swim, they cannot escape and swim with the same velocity as unexposed embryos (Fig. 1). Examples of the observed behaviors can be viewed at the following website: http:// www.uchsc.edu/sp/sp/faculty/Tanguay/presentation_videos.htm.

Continuous exposure to nicotine, beginning at $22 \mathrm{hpf}$, did not produce gross morphological abnormalities in embryos (Fig. $2 A$ ). Measurements of the embryonic lengths (from the tip of the snout to the tailbud) indicated that nicotine exposure did affect overall growth. There was no significant difference in the length of $42 \mathrm{hpf}$ embryos (controls, $2892 \pm 21 \mu \mathrm{m}, n=49$; treated, $2851 \pm 18 \mu \mathrm{m}$,
A
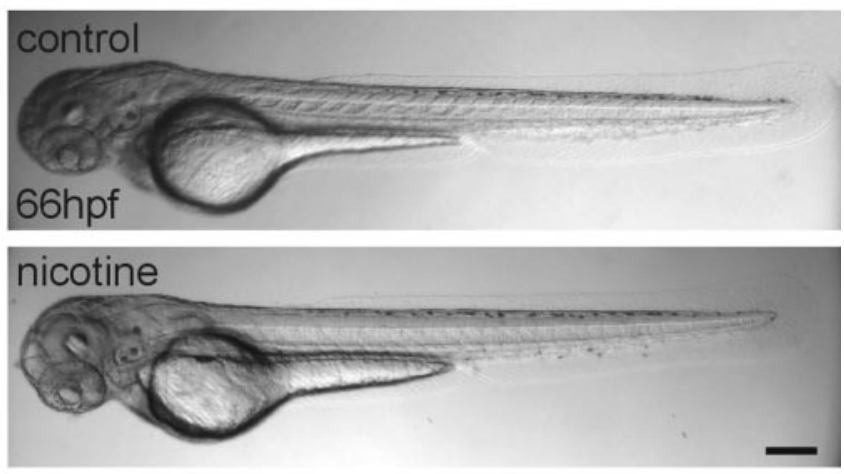

B

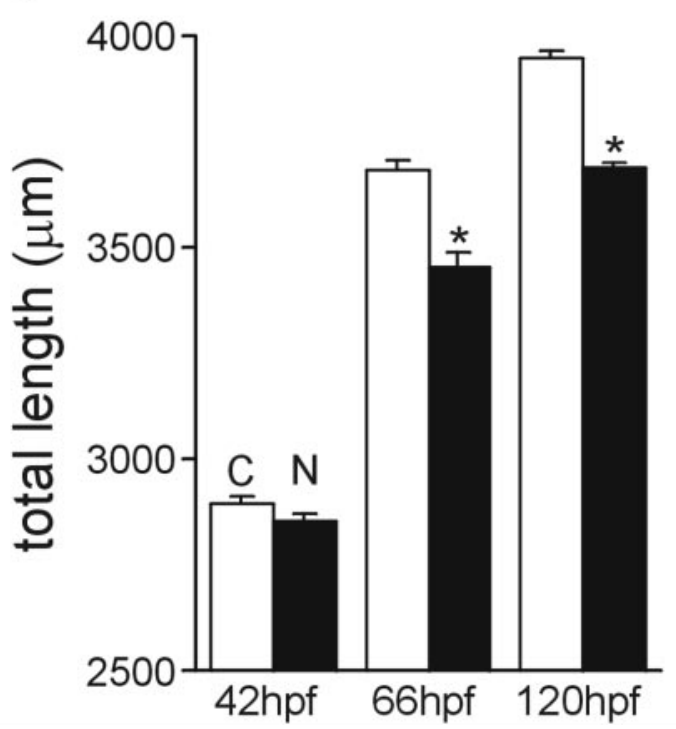

Figure 2. Development of zebrafish embryos exposed to nicotine: gross morphology. $A$, Photomicrographs of a $66 \mathrm{hpf}$ control zebrafish embryo and a stage-matched embryo exposed to $33 \mu \mathrm{M}$ nicotine beginning at 22 hpf. $B$, Summary of overall lengths of control embryos $(C)$ and embryos exposed to nicotine $(N)$ measured at 42, 66, and 120 hpf. Scale bar, 200 $\mu \mathrm{m}$. ${ }^{*} p<0.001$.

$n=49 ; p=0.132)$. At $66 \mathrm{hpf}$, the nicotine-exposed animals were on average $5 \%$ shorter than controls (controls, $3680 \pm 25 \mu \mathrm{m}, n=$ 40; treated, $3455 \pm 31 \mu \mathrm{m}, n=40 ; p<0.001)$. At $120 \mathrm{hpf}$, embryos exposed to nicotine were $6.6 \%$ shorter than stagematched controls (controls, $3947 \pm 20 \mu \mathrm{m}, n=49$; treated, $3688 \pm 15 \mu \mathrm{m}, n=49 ; p<0.001)$ and were statistically similar to the length of the control 66 hpf embryos (Fig. 2B).

\section{Nicotinic effects on nervous system development in embryonic zebrafish}

The behavioral deficits induced in embryos treated with nicotine suggested a problem with neuromusculature function. In fact, these embryos behave somewhat like the nic-1 and sofa potato paralytic zebrafish mutants that have been well characterized (Westerfield et al., 1990; Ono et al., 2001). However, embryos exposed to nicotine perceive touch stimuli. Therefore, we pro- 
A
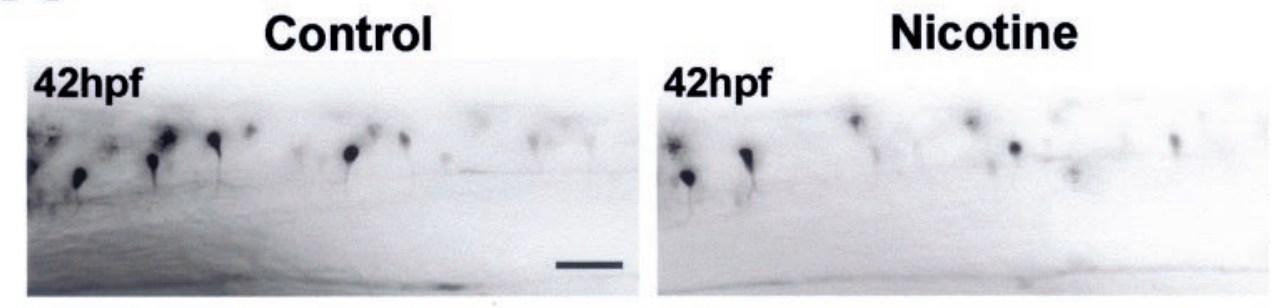

Figure 3. Nicotine alters nervous system development as revealed by in vivo GFP imaging. $A$, Photomicrographs of the rostral regions of spinal cord from control and nicotine-exposed (33 $\mu \mathrm{M})$ islet-1 GFP transgenic zebrafish embryos at 42 and 66 hpf. The insets are photomicrographs of the heads of the embryos from which spinal cord images were taken; they provide orientation for these images as well as all subsequent images in the paper. Arrows illustrate ventral motoneuron axons expressing GFP. B, Photomicrographs of z-series projections that were reconstructed from images acquired in the rostral region of the spinal cord for $66 \mathrm{hpf}$ control and $33 \mu \mathrm{M}$ nicotine-exposed embryos. Scale bars, $40 \mu \mathrm{m}$. For quantitative analysis, segments $2-7$ of the spinal cord were analyzed.
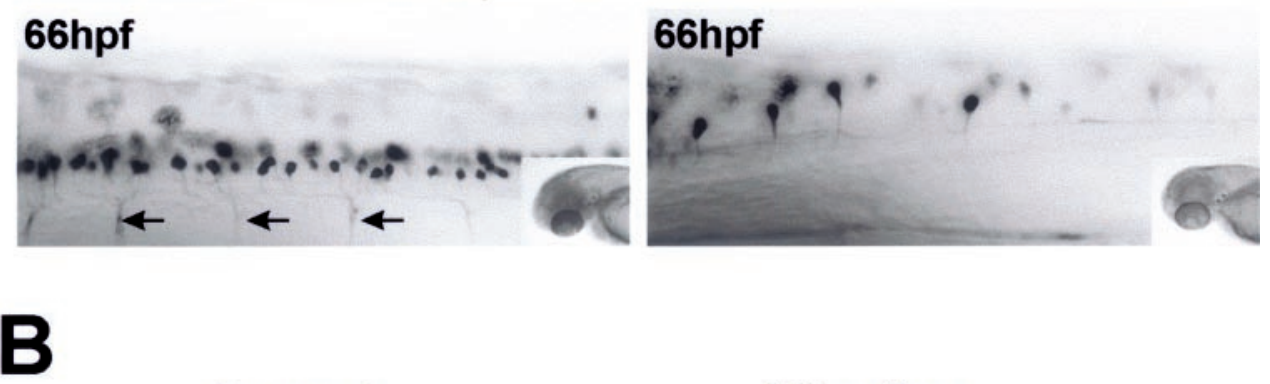

Control

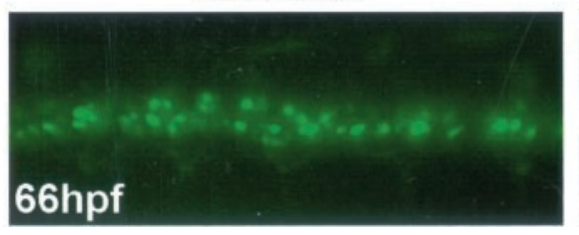

Nicotine

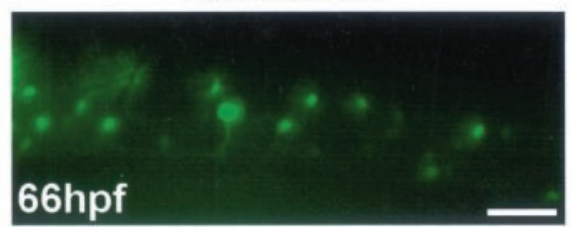

posed that there was a problem either with neuromuscular development, as with the sofa potato mutants, or with the development of the motoneurons innervating the muscle. Because nicotine has been shown to affect motoneuron development and function in other systems (Hory-Lee and Frank, 1995; Oppenheim et al., 2000), we chose to focus our efforts on the effects of the drug on zebrafish motoneuron development and function.

Embryos expressing GFP under the control of the islet-1 promoter were used to detect differences in spinal motoneuron development after nicotine exposure. At $42 \mathrm{hpf}$, there was no difference in the number of rostral spinal GFP-positive motoneurons (segments 2-7 analyzed) in control embryos $(7.1 \pm 0.7 ; n=$ 10) or $33 \mu \mathrm{M}$ nicotine-exposed islet-1 GFP embryos (7.5 \pm 085 ; $n=10$ ) (Fig. $3 A$ ). As early as $54 \mathrm{hpf}$, there were detectable differences between control and nicotine-exposed embryos (data not shown). These differences were pronounced at 66 hpf (Fig. $3 A$ ). In this developmental time period, GFP-positive neurons are easily detected in rostral regions of the spinal cord in control embryos $(31.3 \pm 2.3 ; n=6)$, and GFP expression can be detected in the ventral secondary motoneuron axons. In embryos exposed to nicotine, the number of GFP-positive motoneurons in the rostral spinal cord has increased slightly $(11 \pm 0.74 ; n=9)$, but the GFP expression in the ventral axons was not yet detectable. To rule against the remote possibility that we were missing GFP-positive cells in our single-focal-plane image analysis, embryos were optically sectioned. Sixty-four $0.5 \mu \mathrm{m}$ consecutive images in the region of the rostral spinal cord were acquired and then compressed into a single image. The reconstructed projections of $66 \mathrm{hpf}$ control and $66 \mathrm{hpf}$ nicotine-exposed embryos are shown in Figure $3 B$ and indicate that only a few GFP-positive neurons are present in embryos exposed to nicotine.

\section{Exposure to nicotine delays motoneuron differentiation in embryonic zebrafish}

At $66 \mathrm{hpf}$, there were few if any GFP-expressing motoneurons in the spinal cords of embryos exposed to nicotine. There are two potential explanations for this observation. First, exposure to nicotine may induce secondary motoneuron death. Alternatively, exposure to nicotine may delay the differentiation of spinal secondary motoneurons (i.e., a delay in GFP expression). To distinguish between these two possibilities, embryos were raised in nicotine from 22 to $66 \mathrm{hpf}$ and then raised in drug-free media until $120 \mathrm{hpf}$ (rescued). The GFP expression pattern is greater in these $120 \mathrm{hpf}$ rescued embryos than in the $66 \mathrm{hpf}$ nicotineexposed embryos (Fig. 4A). In fact, at $120 \mathrm{hpf}$, somatic GFP expression patterns between these previously nicotine-exposed embryos and control animals never exposed to nicotine are indistinguishable. These results are not consistent with an early apoptotic elimination of developing spinal secondary motoneurons.

It appeared that the GFP expression patterns were now similar between control and rescued embryos at $120 \mathrm{hpf}$. However, careful analysis of axonal trajectories in rescued embryos indicates that the secondary motoneurons in those embryos are still delayed in the differentiation process compared with the $120 \mathrm{hpf}$ unexposed embryos (Fig. 4B). In embryos never exposed to nicotine, axons in the dorsal myotome have an elaborate GFP expression pattern (Fig. 4B) [Ono et al. (2001), their Fig. 1]. GFP expression in the axons innervating the dorsal musculature of embryos that were exposed to nicotine from 22 to $66 \mathrm{hpf}$ and then rescued was not as extensive as in the control embryos that were never exposed to nicotine. These results also indicate that nicotine delays secondary motoneuron development and that this delay persists into larval developmental stages. 
A

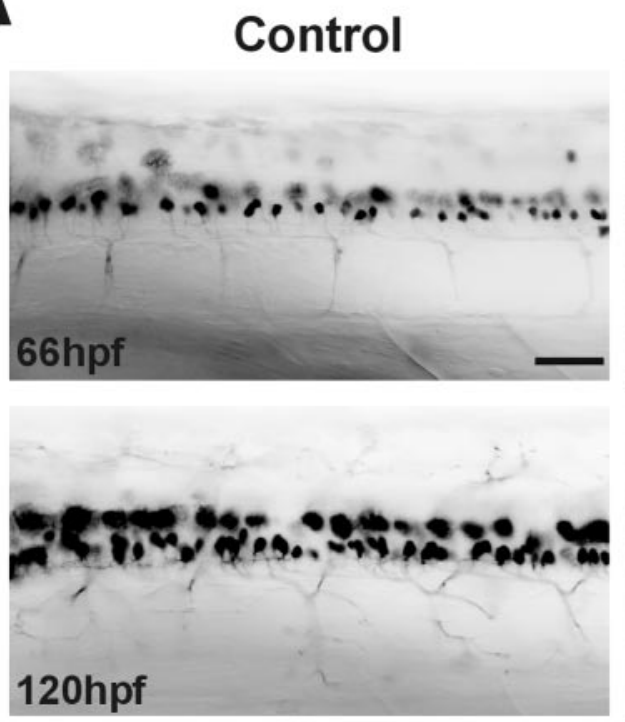

\section{Control}
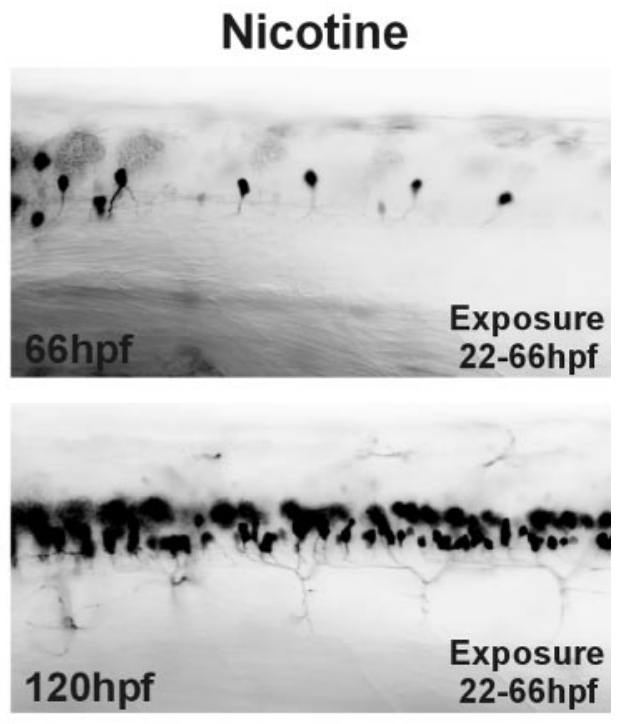

\section{B}
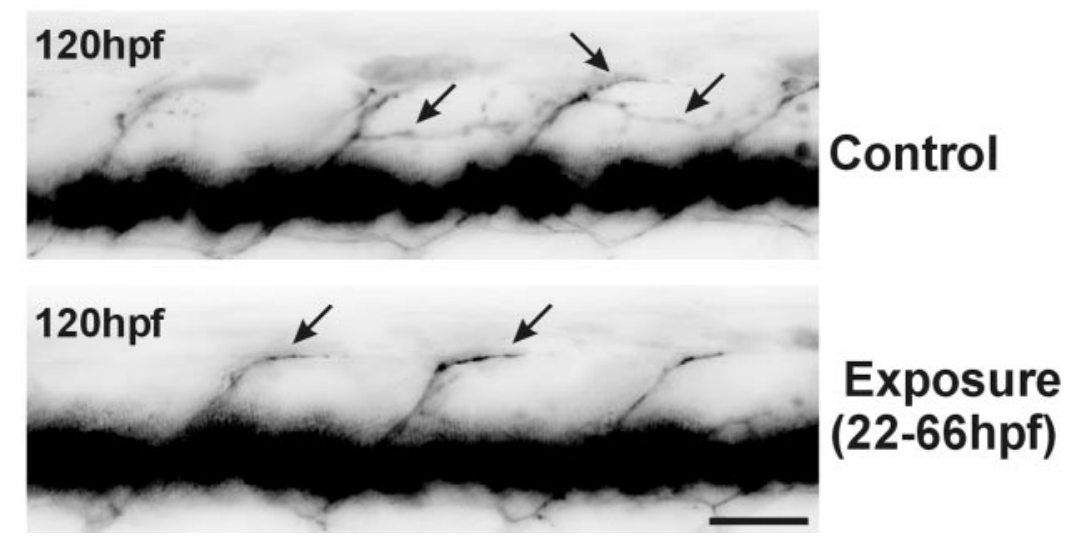

Figure 4. Nicotine-mediated delay in motoneuron GFP expression in $66 \mathrm{hpf}$ embryos. Photomicrographs from islet-1 GFP transgenic embryos are shown. A, In vivo GFP imaging of the rostral spinal cord of control embryos at both 66 and $120 \mathrm{hpf}$, a $66 \mathrm{hpf}$ embryo exposed to $33 \mu \mathrm{M}$ nicotine from 22 to $66 \mathrm{hpf}$, and a $120 \mathrm{hpf}$ embryo exposed to $33 \mu \mathrm{M}$ nicotine from 22 to 66 hpf and then returned to embryo medium until 120 hpf. $B$, Photomicrographs of caudal spinal cord. Arrows indicate dorsal secondary motoneuron axons expressing GFP from a $120 \mathrm{hpf}$ control embryo and a 120 hpf embryo that was exposed to $33 \mu \mathrm{M}$ nicotine between 22 and $66 \mathrm{hpf}$. For imaging, the exposure time was adjusted to detect GFP in the axons. Such exposure times caused the GFP signal in the spinal cords to be saturated (continuous black). Scale bars, $40 \mu \mathrm{m}$.

\section{Exposure to nicotine delays motoneuron differentiation: pharmacological properties}

Most of our experiments were performed using a $33 \mu \mathrm{M}$ concentration of nicotine. This concentration was chosen because it dramatically altered the behavior of the embryo. Using these behavioral criteria, we were confident that nicotine was effectively penetrating the embryo. The precise embryonic dose after our waterborne exposures was not determined in these studies. To assess exposure concentration effects, islet-1 GFP embryos were exposed to 5,15 , and $33 \mu \mathrm{M}$ nicotine followed by in vivo GFP imaging at $66 \mathrm{hpf}$ (Fig. $5 \mathrm{~A}$ ). A $5 \mu \mathrm{M}$ concentration of nicotine had little effect on GFP expression, and the embryos swam vigorously in response to touch. A decrease in the number of GFP-positive neurons as well as GFP-expressing ventral axons was apparent in embryos exposed to $15 \mu \mathrm{M}$ nicotine, but the behavior of these embryos appeared normal (data not shown). A severe reduction in GFP-expressing motoneurons, as well as a behavioral deficit, was observed in embryos that were exposed to $33 \mu \mathrm{M}$ nicotine (Fig. 5A). Behaviorally, these embryos responded to touch but could not swim.

To determine whether the effects of nicotine in zebrafish were mediated by nAChRs, known mammalian neuronal nicotinic an- tagonists were tested for their ability to reverse the effects of 33 $\mu \mathrm{M}$ nicotine. For these studies, antagonists were added $2 \mathrm{hr}$ before the addition of nicotine. $\mathrm{DH} \beta \mathrm{E}$, an $\alpha 4 / \beta 2$ subtype-selective $\mathrm{nAChR}$ antagonist in chicks and mammals, blocked the action of nicotine (Fig. 5B,C). The $\alpha 7$ subtype receptor-selective antagonist MLA failed to reverse the nicotine effects when used at a concentration of $100 \mathrm{nM}$. At a concentration of $2 \mu \mathrm{M}$, at which it can interact with other nAChR subtypes (Ward et al., 1990), MLA was capable of blocking the actions of nicotine on the motoneuron phenotype (Fig. 5C). However, because neither the concentration of the drugs at the motoneurons nor the nAChR pharmacology in zebrafish is known, it would be premature to comment on the subtypes of the receptors responsible. What the result does permit us to conclude is that the actions of nicotine are attributable to its actions on nAChRs.

Consistent with this conclusion, when coapplied with nicotine, both antagonists failed to alleviate the nicotine-induced behavioral deficits, because the embryos were still functionally paralyzed. This would be the expected result, because both antagonists are nAChR-specific and would not be expected to reverse a muscle nicotinic receptor-mediated paralysis. DH $\beta \mathrm{E}$ and MLA by themselves did not affect the behavior of the embryo or the 
Figure 5. Pharmacology of the action of nicotine in embryonic zebrafish. $A$, Summary graph indicating that nicotine acts in a concentration-dependent manner. In the rostral spinal cord of $66 \mathrm{hpf}$ islet-1 embryos, ventral myotomes were analyzed to assess whether their motoneuron axons expressed GFP (see Materials and Methods). For example, in the case of controls (Con), of 339 ventral myotomes analyzed in 56 embryos, $291(85 \pm 3 \%)$ had axons that expressed GFP. For embryos treated with a $5 \mu \mathrm{M}$ concentration of nicotine ( $n=13$ embryos), $84.7 \pm$ $8.7 \%$ of the ventral myotomes contained axons expressing GFP; for embryos treated with a $15 \mu \mathrm{M}$ concentration $(n=$ 31 embryos), $38.3 \pm 8.1 \%$ of the ventral myotomes contained axons expressing GFP; for embryos treated with a $33 \mu \mathrm{M}$ concentration ( $n=56$ embryos), $20.8 \pm$ $4.5 \%$ of the ventral myotomes contained axons expressing GFP. * $p<0.0001$ (significantly different from control); ${ }^{+} p<$ 0.05 (significant differences between embryos treated with 33 and $15 \mu \mathrm{M}$ ). $B$, Photomicrographs of a rostral region of spinal cord from a $66 \mathrm{hpf}$ control embryo, an embryo exposed to $33 \mu \mathrm{M}$ nicotine alone, or an embryo exposed to $33 \mu \mathrm{M}$ nicotine plus $20 \mu \mathrm{M} \mathrm{DH} \beta \mathrm{E}$. $C$, Summary graph of antagonist data in which the analysis was performed as in $A$. For embryos treated with a $33 \mu \mathrm{M}$ concentration of nicotine (Nic) $(n=56$ embryos), $20.8 \pm 4.5 \%$ of the ventral myotomes contained axons expressing GFP; for embryos treated with a $100 \mathrm{nM}$ concentration of MLA plus a $33 \mu \mathrm{M}$ concentration of nicotine ( $n=13$ embryos), $22.0 \pm 6.6 \%$ of the ventral myotomes contained axons expressing GFP; for embryos treated with a $2 \mu \mathrm{M}$ concentration of MLA plus a $33 \mu \mathrm{M}$ concentration of nicotine $(n=$ 11 embryos), $90.7 \pm 6.4 \%$ of the ventral myotomes contained axons expressing GFP); for embryos treated with a $20 \mu \mathrm{M}$ concentration of DH $\beta$ E plus a $33 \mu \mathrm{M}$ concentration of nicotine $(n=10$ embryos $), 84.2 \pm 7.9 \%$ of the ventral myotomes contained axons expressing GFP. Scale bar, $40 \mu \mathrm{m}$. ${ }^{*} p<0.0001$ (significance differences compared to $33 \mu \mathrm{M}$ nicotine exposed).

timing of GFP expression in secondary motoneurons (data not shown).

\section{Exposure to nicotine delays markers of secondary motoneuron differentiation in zebrafish embryos}

One possible interpretation of the results of the nicotinemediated alteration of GFP expression in the islet-1-GFP embryo is that the nicotine is merely affecting the expression of GFP rather than having an impact on the development of the cells expressing GFP. To rule out this possibility, experiments were performed in nontransgenic zebrafish embryos using the zn5 immunocytochemical marker. This antibody recognizes the cell adhesion molecule DM-GRASP (Burns et al., 1991) and is a reliable marker for zebrafish spinal secondary motoneurons (Beattie et al., 1997; Fashena and Westerfield, 1999). In $42 \mathrm{hpf}$ embryos, zn5 immunolabeling patterns are similar in both control and nicotine-exposed embryos (Fig. 6A, top). At this time, zn5 easily detects the DM-GRASP adhesion molecule in many spinal secondary motoneurons and also in their ventrally projecting axons. At 66 hpf, DM-GRASP was somatically downregulated in control embryos (Fig. 6A, bottom left). This is revealed by the weak zn5 labeling of motoneuron somata. However, the zn5 antibody still robustly labels ventrally as well as dorsally projecting axons of control embryos. In $66 \mathrm{hpf}$ embryos that were exposed to nicotine, zn5 still labels the motoneuron soma (Fig. $6 \mathrm{~A}$, bottom right); this pattern was very similar to the labeling observed for zn5 labeling in the younger control embryos (com- pare with Fig. $6 A$, top left). However, dorsally projecting axons have not extended into the periphery at $66 \mathrm{hpf}$ in the nicotineexposed embryos.

Our results to this point indicate that nicotine dramatically alters motoneuron differentiation. To determine whether this effect is specific to secondary motoneurons, another neuronal marker was used to detect other spinal neurons. The monoclonal antibody znS5 labels dorsal and ventral spinal neurons (Institute of Neuroscience, University of Oregon) in embryonic zebrafish. In 42 hpf embryos, znS5 labels ventral spinal neurons, which are likely to be motoneurons, and dorsal spinal neurons, which we presumed to be interneurons. It also labels ventrally projecting motoneuron axons in $42 \mathrm{hpf}$ embryos (Fig. 6B, top left). Nicotine exposure had no apparent effect on this expression pattern in 42 hpf embryos. (Fig. 6B, top). At $66 \mathrm{hpf}$, znS5 is downregulated in dorsal and ventral spinal neurons of unexposed embryos (Fig. 6B, bottom left). As was the case for zn5 labeling, ventrally as well as dorsally projecting motoneuron axons are easily detected by znS5. In embryos exposed to nicotine, the $\mathrm{znS} 5$ expression persists in many spinal neurons at $66 \mathrm{hpf}$, indicating a delay in the normal downregulation program. Furthermore, although ventral axons were labeled, dorsally projecting axons were difficult to detect (Fig. 6B, bottom right).

To further demonstrate that nicotine is having an impact on spinal neuronal differentiation rather than simply altering GFP expression, GFP/zn5 double-labeling experiments were performed 
A

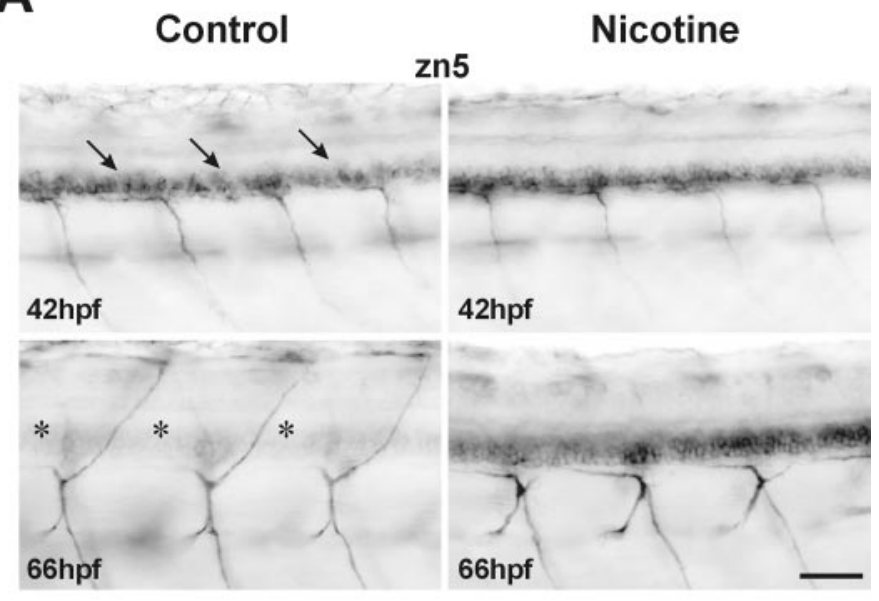

B

Control

znS5

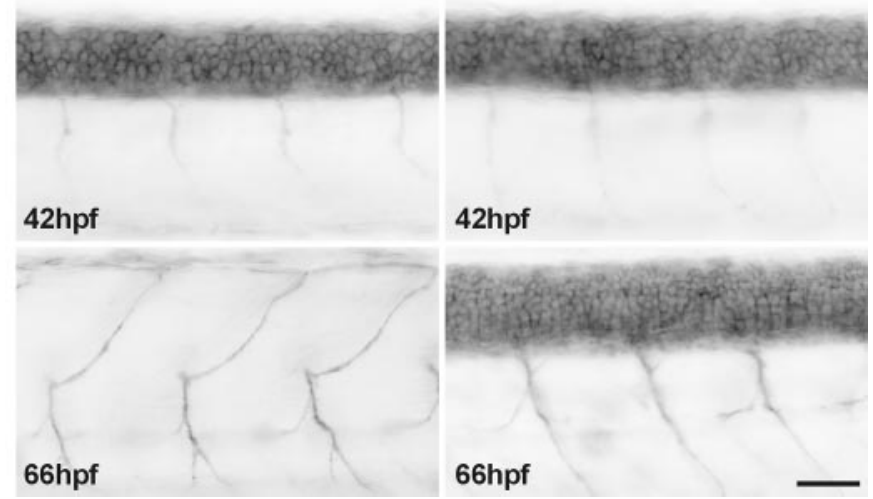

Figure 6. Immunocytochemistry confirms the nicotine-mediated delay of spinal motoneuron development. $A$, zn5 immunohistochemical photomicrographs of the caudal region of spinal cord from controls and embryos exposed to $33 \mu \mathrm{M}$ nicotine from 22 to 42 and $66 \mathrm{hpf}$ ( $42 \mathrm{hpf}$ control, $n=$ 9; $66 \mathrm{hpf}$ control, $n=11 ; 42 \mathrm{hpf}$ nicotine, $n=8$; 66 hpf nicotine, $n=14$ ). The zn5 antibody labels secondary motoneuron somata (arrows) as well as ventrally projecting motoneuron axons in control $42 \mathrm{hpf}$ embryos. In control $66 \mathrm{hpf}$ embryos, zn5 labels ventrally as well as dorsally projecting motoneuron axons, but somata labeling is faint (asterisks). In the $42 \mathrm{hpf}$ embryo exposed to nicotine, zn5 labels secondary motoneuron somata and ventrally projecting motoneuron axons. In $66 \mathrm{hpf}$ embryos exposed to nicotine, zn5 robustly labels secondary motoneuron somata and axons that project ventrally. Dorsally projecting axons are not detected by zn5 in the $66 \mathrm{hpf}$ embryo exposed to nicotine. $B$, Experiments were performed as in $A$, but the znS5 antibody was used in place of zn5. In nonexposed 42 hpf embryos $(n=14)$, spinal neuron somata as well as ventrally projecting motor axons are detected by the znS5 antibody. At $66 \mathrm{hpf}$ in control embryos $(n=23)$, znS5 detects ventral and dorsal motoneuron axons but not spinal neuron somata. In $42 \mathrm{hpf}$ embryos exposed to nicotine $(n=13)$, spinal neuron somata as well as ventrally projecting motor axons are detected by the znS5 antibody. In 66 hpf nicotine-exposed embryos, znS5 detects ventral motoneuron axons and spinal neuron somata $(n=22)$. Scale bars, $40 \mu \mathrm{m}$.

in nicotine-exposed $66 \mathrm{hpf}$ transgenic embryos (Fig. 7). The red zn5 fluorescence is intense, indicating that the secondary motoneurons are present; however, these cells do not yet express GFP. The few GFP-positive cells in the image are likely interneurons.

When embryos were withdrawn from nicotine at $66 \mathrm{hpf}$ and then analyzed at $120 \mathrm{hpf}$, both the zn5 and znS5 (data not shown) labeling had been significantly downregulated in spinal neuron

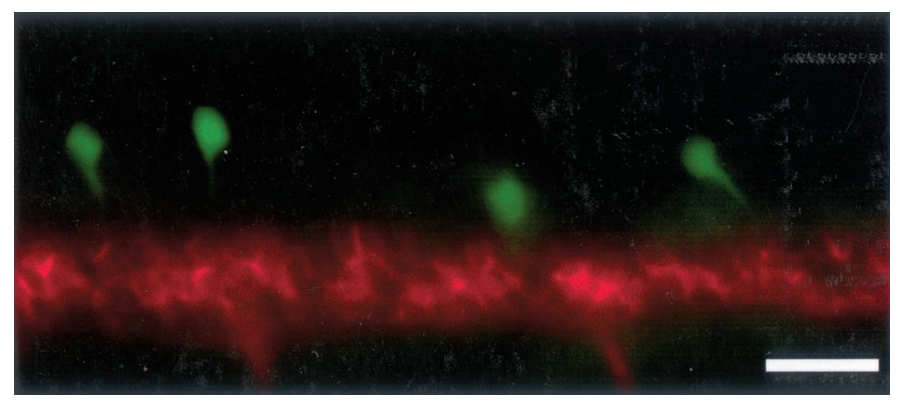

Figure 7. Detection of secondary motoneurons by simultaneous GFP imaging and zn5 immunohistochemistry. A photomicrograph of the rostral spinal cord from a $66 \mathrm{hpf}$ transgenic islet-1-GFP embryo that was exposed to $33 \mu \mathrm{M}$ nicotine from 22 to $66 \mathrm{hpf}$ is shown. Red fluorescence indicates zn5-positive cells; the green fluorescence is from the GFP expression. Secondary motoneurons (zn5) are abundant at this developmental point; however, they do not express GFP. The few dorsal GFP-positive cells are likely to be interneurons. This rules against the idea that nicotine is inducing apoptosis in spinal secondary motoneurons of zebrafish embryos. The secondary motoneurons are indeed present; they just fail to express GFP. Scale bar, $20 \mu \mathrm{m}$.

somata. However, the DM-GRASP (zn5) remained detectable in 13 of the 15 exposed and in only three of the 15 control embryos (Fig. 8A, asterisks). Furthermore, in these rescued embryos, ventral as well as dorsal axons were now easily detected with either molecular marker (Fig. $8 B$ ), but the dorsally projecting axons were delayed in extending into the periphery (Fig. $8 \mathrm{~A}$, bottom, arrow). Pathfinding errors in rescued embryos persisted as late as $192 \mathrm{hpf}$. Specifically, dorsally projecting axons failed to follow the stereotyped trajectories apparent for dorsal axons in control embryos (Fig. 9A), but instead often made inappropriate turns and often failed to reach their peripheral targets. Behaviorally, these rescued embryos all responded robustly to tactile stimulation. However, their swimming behavior was dramatically impaired. Rescued embryos failed to swim with the same velocity on tactile stimulation when compared with controls (see http://www. uchsc.edu/sp/sp/faculty/Tanguay/presentation videos.htm). If nicotine was withdrawn at 72 rather than $66 \mathrm{hpf}$, the axons innervating the dorsal musculature were even more severely stunted and had serious deficits in pathfinding (Fig. 9B).

\section{DISCUSSION}

In this paper, we assessed the impact of nicotine exposure on the developing zebrafish embryo. Using three independent assays [secondary motoneuron GFP expression, expression of DMGRASP (an adhesion molecule recognized by the monoclonal antibody zn5), and expression of an unidentified antigen recognized by the monoclonal antibody znS5], we show that the development of spinal secondary motoneurons as well as other spinal neurons is delayed by nicotine exposure via a mechanism involving $\mathrm{nAChR}$ activation. We also demonstrate that nicotine delays as well as alters axonal pathfinding in secondary motoneurons. We suggest that the abnormalities in motoneuronal anatomy may have long-term consequences on larval zebrafish behavior.

\section{Nicotine delays the differentiation of spinal neurons}

Secondary motoneurons are a population of spinal neurons that comprise most of the motor pool in the developing zebrafish. There are $\sim 30$ secondary motoneurons per hemisegment; they begin extending their axons at 23 hpf (Myers et al., 1986; Pike et al., 1992). Their axons extend into the periphery by following the axonal pathways that have been laid down by the primary motoneu- 
A

\section{Control}

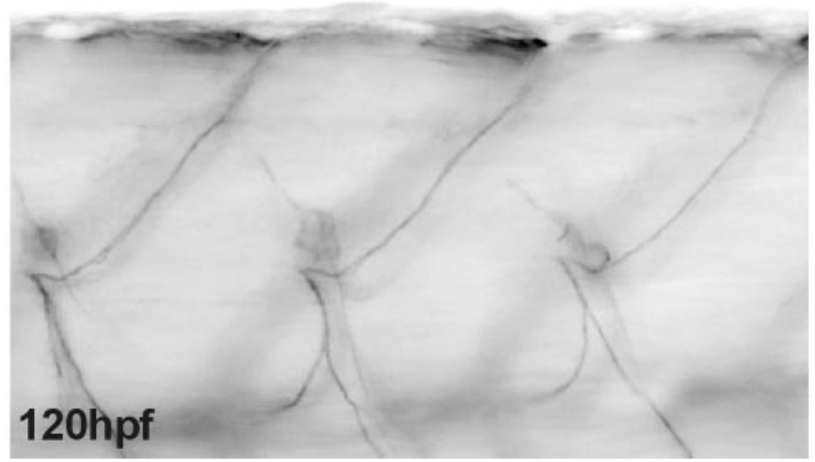

\section{Nicotine (exposure 22-66hpf)}

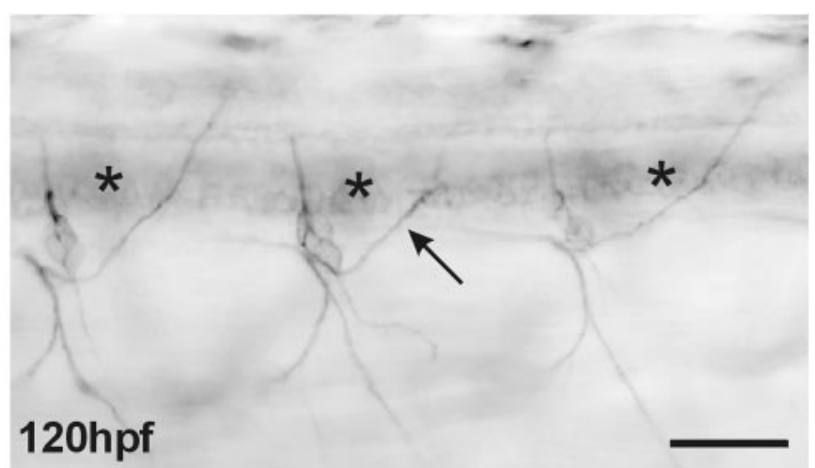

B

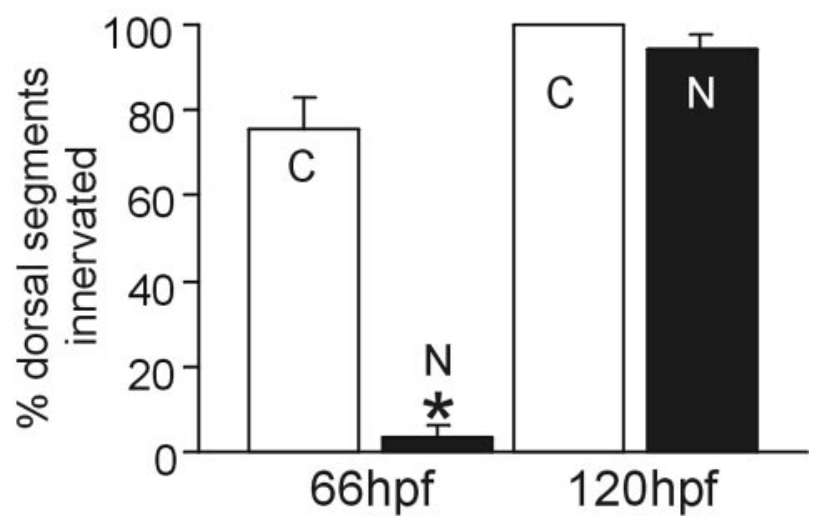

Figure 8. Nicotine delays secondary motoneuron differentiation as well as axonal pathfinding of secondary motoneurons. $A$, zn5 immunohistochemical photomicrographs of caudal spinal cord from $120 \mathrm{hpf}$ control and an embryo exposed to $33 \mu \mathrm{M}$ nicotine from 22 to $66 \mathrm{hpf}$. zn5 labels dorsal and ventral axons in control $(n=15)$ and nicotine-exposed $(n=$ 15) embryos. In the nicotine-exposed embryo, the labeling of somata is still apparent (asterisks). Dorsally projecting axons are delayed in extending into the periphery (arrow). B, In 66 and $120 \mathrm{hpf}$ embryos, dorsal myotomes were analyzed to assess whether motoneuron axons had innervated the dorsal musculature. For example, in the case of $66 \mathrm{hpf}$ controls, 44 of 59 total myotomes analyzed contained axons of secondary motoneurons that extended into the dorsal myotome. For 66 hpf controls $(n=11$ embryos), $74.5 \pm 7.1 \%$ dorsal myotomes were innervated; for $66 \mathrm{hpf}$ embryos exposed to nicotine ( $n=14$ embryos), $3.6 \pm 1.0 \%$ of dorsal rons (Eisen et al., 1986; Melancon et al., 1997). Taking advantage of the recently well characterized secondary motoneuron-specific islet-1 promoter-driven GFP transgenic fish, we show that nicotine affects secondary motoneuron development in zebrafish.

At $42 \mathrm{hpf}$, GFP is initially detected in spinal neuron somata of the untreated islet- 1 transgenic embryo. By 66 hpf, GFP expression is upregulated in secondary motoneuron somata, and ventrally projecting axons also contain GFP. By $120 \mathrm{hpf}$, GFP is abundant in secondary motoneuron somata, ventrally projecting motoneuron axons, and dorsally projecting motoneuron axons. In embryos exposed to nicotine, GFP expression is not increased in $66 \mathrm{hpf}$ embryos. The number of GFP-expressing motoneuron somata was significantly lower than that of stage-matched control embryos, and GFP was not detectable in ventrally projecting axons. One possible interpretation of these results is that motoneurons were being eliminated by nicotine exposure. Nicotinemediated apoptosis has been observed in hippocampal progenitor cells (Berger et al., 1998). If nicotine induced cell death in secondary motoneurons, we would predict that GFP expression would remain low in the embryos initially exposed to nicotine and then rescued and raised in embryo medium. However, when zebrafish embryos were exposed to nicotine between 22 and 66 hpf and then placed back into nicotine-free medium until $120 \mathrm{hpf}$ (rescued), abundant expression of GFP was detected in motoneuron somata, ventrally projecting motoneuron axons, and dorsally projecting motoneuron axons. Importantly, with careful anatomical inspection, the GFP expression in dorsal axons of these 120 hpf rescued embryos was not as elaborate as control embryos. Together, these results indicate that nicotine delays secondary motoneuron differentiation.

The zn5 antibody is often used to recognize axons of secondary motoneurons as well as their somata in embryonic zebrafish (Beattie et al., 1997; Fashena and Westerfield, 1999). In 42 hpf control embryos, zn5 labels spinal secondary motoneuron somata as well as ventrally projecting axons. At $66 \mathrm{hpf}$, zn5 labels only ventral and dorsal motoneuron axons but not motoneuron somata. The DM-GRASP antigen recognized by zn5 is downregulated somatically after axons have innervated their muscle targets. Interestingly, as DM-GRASP is being downregulated in embryos, islet-1-driven GFP expression is upregulated in the islet-1 transgenic embryos. When assayed at $66 \mathrm{hpf}$, embryos exposed to nicotine still retained robust zn5 labeling in their somata. Compared with control animals, zn5 immunolabeling in dorsal axons was difficult to detect in $66 \mathrm{hpf}$ embryos exposed to nicotine. This suggests that the dorsal axons arising from secondary motoneurons in embryos exposed to nicotine have not extended into the periphery and innervated the musculature. When embryos were removed from nicotine at $66 \mathrm{hpf}$ and then assayed at $120 \mathrm{hpf}$, zn5 was detected in dorsally and ventrally projecting axons. Thus, nicotine delayed the downregulation of DMGRASP possibly by delaying innervation of the musculature, as hypothesized previously (Fashena and Westerfield, 1999). These experiments, in conjunction with the GFP results, indicate that nicotine delays motoneuron development and does not induce secondary motoneuron apoptosis. If nicotine did induce second-

myotomes were innervated; for $120 \mathrm{hpf}$ controls $(n=15$ embryos $), 100 \%$ of dorsal myotomes were innervated; for $120 \mathrm{hpf}$ rescued embryos (exposed to $33 \mu \mathrm{M}$ nicotine from 22 to $66 \mathrm{hpf} ; n=15$ embryos), $94.6 \pm 3.0 \%$ of segments were innervated. ${ }^{*} p<0.00001$. $N$, A $33 \mu \mathrm{M}$ concentration of nicotine from 22 to 66 hpf. $C$, Controls. Scale bar, $40 \mu \mathrm{m}$. 
A

\section{Control}

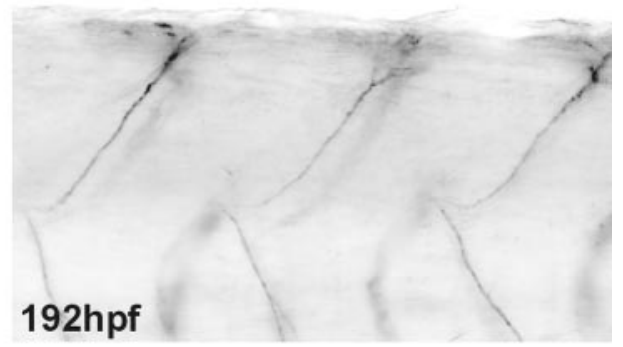

Nicotine (exposure 22-66hpf)

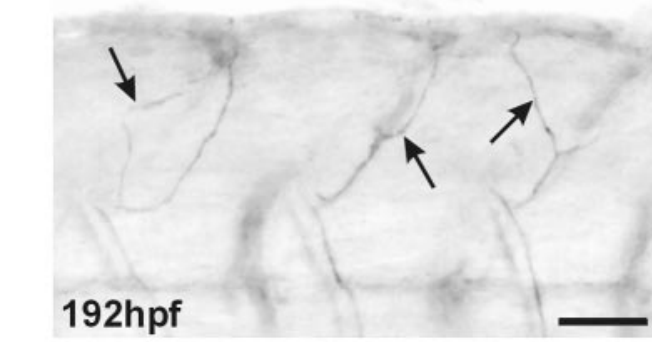

B
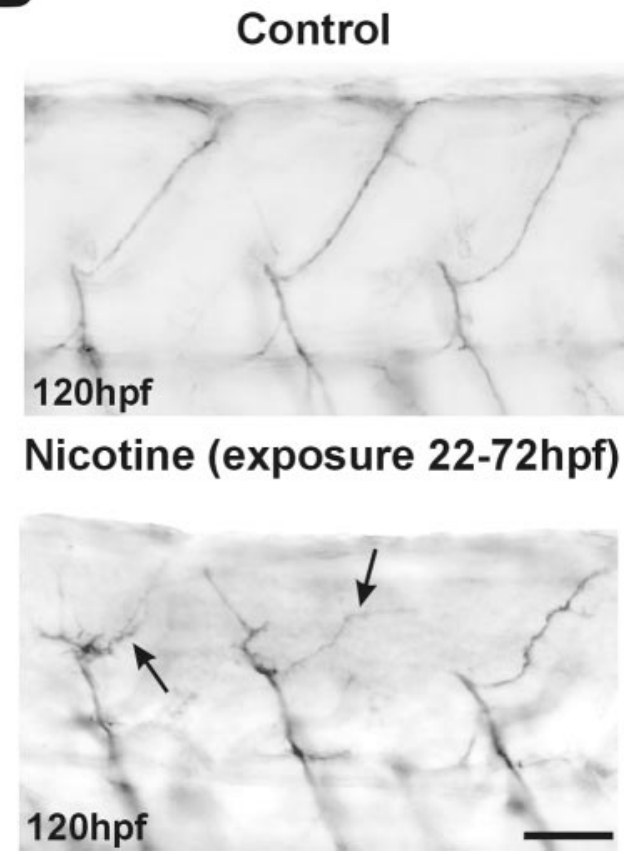

Figure 9. Nicotine induces pathfinding errors in the axons of secondary motoneurons. $A$, Photomicrographs of caudal regions of the spinal cord in $192 \mathrm{hpf}$ embryos. znS5 labels dorsally and ventrally projecting motoneuron axons, but not somata, in both controls (top, $n=8)$ and embryos exposed to $33 \mu \mathrm{M}$ until $66 \mathrm{hpf}$ (bottom, $n=10$ ) and then returned to embryo medium. The dorsal axons of the $192 \mathrm{hpf}$ nicotineexposed embryo take incorrect pathways to the periphery (arrows). B, Photomicrographs of the caudal spinal cord from control $120 \mathrm{hpf}$ embryos (top, $n=17$ ) and $120 \mathrm{hpf}$ embryos exposed to $33 \mu \mathrm{M}$ nicotine until $72 \mathrm{hpf}$ and then returned to embryo medium (bottom, $n=6$ ). znS5 labels the dorsal axons in all embryos; axons of embryos rescued from nicotine at $72 \mathrm{hpf}$ are stunted and show significant problems in pathfinding (arrows). Scale bars, $40 \mu \mathrm{m}$. ary motoneuron apoptosis, zn5-positive cells should not be detected in motoneuron somata at $66 \mathrm{hpf}$ in embryos exposed to 33 $\mu \mathrm{M}$ nicotine. This is clearly not the case. At $66 \mathrm{hpf}$, zn5-positive cells are clearly present in embryos exposed to nicotine, whereas GFP expression in these motoneurons is minimal. This is clearly demonstrated in GFP/zn5 double-labeled nicotine-exposed 66 hpf transgenic embryos. The red zn5 fluorescence is robust, indicating that secondary motoneurons are present; however, these cells do not yet express GFP.

The results using another neuronal marker, znS5, which labels ventral spinal motoneurons and dorsal spinal neurons, supports the conclusion that nicotine delays nervous system development. The antigen recognized by $\mathrm{znS} 5$ is downregulated somatically during development, and this expression is very similar to that observed for zn5. In control embryos, the somatic signal was greatly diminished by $66 \mathrm{hpf}$, but the axonal signals remained intense up to $192 \mathrm{hpf}$. Nicotine exposure also results in a delay in this programmed downregulation of the znS5 marker, because somatic labeling persists in $66 \mathrm{hpf}$ embryos. This provides a third line of evidence that nicotine delays motoneuron differentiation; it also indicates that nicotine delays differentiation of other dorsal spinal neurons (likely interneurons) (Kuwada et al., 1990; Hale et al., 2001). Clearly, the effects of nicotine are not restricted to secondary motoneuron development in embryonic/larval zebrafish.

\section{nAChRs mediate the actions of nicotine in zebrafish embryos}

Embryos exposed to $15 \mu \mathrm{M}$ nicotine can swim with tactile stimulation, but motoneuron development is delayed in these embryos. This suggests that in the presence of normal muscle activity, nicotine alters secondary motoneuron differentiation via a mechanism dependent on nAChRs. Embryos exposed to $33 \mu \mathrm{M}$ nicotine are functionally paralyzed; hence, any abnormalities in motoneuron development could be related to muscle inactivity. To rule against this possibility, embryos were exposed to nicotine in conjunction with specific nAChR antagonists. High concentrations of MLA, a mammalian $\alpha 7$-containing nAChR-selective antagonist, and a pharmacologically relevant concentration of $\mathrm{DH} \beta \mathrm{E}$ blocked the deleterious actions of nicotine on motoneuron development. Importantly, neither reversed the functional paralysis induced by nicotine. A model consistent with our results is that the nicotine-induced paralysis is likely mediated by inactivation of muscle ACh receptors. Because the loci of action of the two antagonists are neuronal and not muscle, these antagonists would not be expected to reverse muscle-mediated paralysis. However, specific neuronal antagonists would be expected to reverse nicotine-induced neuron-dependent phenotypes, which is what we observed. However, the identification of the nAChR subtypes involved awaits a detailed pharmacological characterization of the zebrafish receptors.

When used alone, the antagonists did not affect behavior or motoneuron anatomy. This implies that endogenous ACh does not have the same effect as nicotine. One explanation is that there is no activation of nAChRs by the ACh released at these developmental stages. This explanation implies that receptor expression precedes that of endogenous agonists. A second possibility is that chronic exposure to agonist (nicotine in this case) has different effects on $\mathrm{nAChR}$ signaling. In either case, our findings suggest that the profound effects of nicotine on development arise from its ability to usurp normal nAChR signaling in the nervous system. 


\section{Nicotine alters axonal pathfinding in zebrafish embryos: a neuronal mechanism}

It has been well documented in zebrafish that normal muscle activity is not required for normal motoneuron development. In the sofa potato paralytic mutant, synaptic transmission at the neuromuscular junction is abolished. However, the morphology of secondary motoneurons and their corresponding axonal trajectories and GFP expression patterns in $120 \mathrm{hpf}$ sofa potato embryos appear to be normal (Ono et al., 2001); they are not stunted or retarded in their development. In the paralytic mutant known as nic-1, ACh receptor function in the muscle is completely blocked. However, motoneuron innervation patterns as well as the neuromuscular junctions in the periphery are normal (Westerfield et al., 1990). Thus, muscle inactivity appears to have no profound effect on secondary motoneuron development, axonal trajectories, or morphology. Embryos exposed to $33 \mu \mathrm{M}$ nicotine are functionally paralyzed at $66 \mathrm{hpf}$, and the dorsal axons of secondary motoneurons do not extend into the periphery. Moreover, in embryos continuously exposed to nicotine until 120 hpf, the axons of secondary motoneurons are also severely stunted (data not shown). These results are in stark contrast to the anatomy of motoneurons of zebrafish paralytic mutants, in which motoneuron axons appear normal, and to motoneurons of the developing chick, in which the axons are actually hyperbranched when muscle activity is blocked (Pittman and Oppenheim, 1979; Westerfield et al., 1990; Landmesser, 1992; Ono et al., 2001). This provides yet another line of evidence suggesting a neuronal mechanism for the action of nicotine in embryonic/ larval zebrafish.

In embryos exposed to nicotine from 22 to $66-72 \mathrm{hpf}$ and then returned to nicotine-free medium until 120 or $192 \mathrm{hpf}$, axons of secondary motoneurons innervating the dorsal musculature are delayed in extending into the periphery. Furthermore, dorsal axons had abnormal trajectories into the periphery. They failed to follow the stereotyped, straight pathway to the periphery taken by control axons. Although our results are inconsistent with studies from paralyzed vertebrates in which muscle receptor function is known to be blocked and axons of motoneurons are unaffected, they are consistent with studies from chick ciliary ganglion, in which nicotine induces the retraction of neurites (Pugh and Berg, 1994). Thus, the abnormalities in axonal trajectories induced by nicotine in zebrafish embryos are likely the result of an unidentified neuronal mechanism and are not necessarily related to nicotine-induced muscle blockade.

\section{Consequences of nicotine exposure on morphology and behavior}

Nicotine-exposed embryos were shorter than control embryos; this difference was evident between 42 and 66 hpf. This appears to be in a critical period when the axons of secondary motoneurons extend to the periphery. At $48 \mathrm{hr}$, it is known that secondary motoneuron axons innervate the myotome (Liu and Westerfield, 1992). Thus, it may be that innervation of muscle by secondary motoneurons is required for the progression of growth to occur in zebrafish embryos.

Embryos continuously exposed to nicotine and assayed behaviorally at 42, 66, or $120 \mathrm{hpf}$ are functionally paralyzed. The paralysis likely results from inactivation of muscle ACh receptors by nicotine exposure. Interestingly, the axons of secondary motoneurons that project dorsally in 66 and $120 \mathrm{hpf}$ embryos continuously exposed to nicotine were dramatically delayed in extending into the periphery versus axons of untreated, stage- matched controls. If secondary motoneurons fail to innervate the musculature properly, this could have a detrimental impact on swimming behavior. Embryos initially exposed to nicotine at 22 $\mathrm{hpf}$ and returned to embryo medium at $66 \mathrm{hpf}$ were not paralyzed when assayed behaviorally at $120 \mathrm{hpf}$ or $168 \mathrm{hpf}$. They reliably responded to tactile stimuli, but their swimming behavior was dramatically impaired. Specifically, these rescued embryos had slower swim speeds compared with controls. This reduction in swim speed likely results from less force generation by the musculature. For example, the force generated by the innervated muscle of an embryo exposed to nicotine will be less than that of control embryos by virtue of having fewer muscle fibers innervated and consequently activated with stimulation (Foreman and Eaton, 1993; Liu and Fetcho, 1999). If less force is generated by the muscle fibers of embryos exposed to nicotine, the escape/swim velocity of those embryos may be less than that of control embryos. Although these behavioral and morphological consequences are consistent with a deficit in motoneuron function, it is also possible that the observed behavioral phenotypes induced by nicotine are independent of the motoneuron deficits reported in this study. It may be that other neurons that comprise the circuitry that generates and maintains swimming are also altered in some manner by nicotine. We are currently investigating these possibilities.

The use of adult zebrafish as a model system to study drug addiction has shown exceptional promise (Darland and Dowling, 2001). However, there is a major gap in our understanding of the developmental consequences of embryonic nicotine exposure. The results of our studies firmly establish the embryonic zebrafish as an excellent research model to elucidate the molecular mechanism(s) and etiology of nicotine-induced neuronal toxicity. It is likely that the diverse and long-term consequences of nicotine exposure reported here involve the actions of more than one gene, and genetic approaches will allow the determination of the genes underlying each phenotype. The unique characteristics of zebrafish will allow rapid gene discovery that should lead to new insights about the prevention and treatment of nicotine-induced neural injury in humans. Clearly, these approaches can be applied to study the mechanism of other drugs of abuse on the development of the vertebrate nervous system or to investigate how drugs of abuse have an impact on the adult vertebrate nervous system.

\section{REFERENCES}

Beattie CE, Hatta K, Halpern ME, Liu H, Eisen JS, Kimmel CB (1997) Temporal separation in the specification of primary and secondary motoneurons in zebrafish. Dev Biol 187:171-182.

Berger F, Gage FH, Vijayaraghavan S (1998) Nicotinic receptor-induced apoptotic cell death of hippocampal progenitor cells. J Neurosci 18:6871-6881.

Burns FR, von Kannen S, Guy L, Raper JA, Kamholz J, Chang S (1991) DM-GRASP, a novel immunoglobulin superfamily axonal surface protein that supports neurite extension. Neuron 7:209-220.

Colquhoun LM, Patrick JW (1997) Pharmacology of neuronal nicotinic acetylcholine receptor subtypes. Adv Pharmacol 39:191-220.

Darland T, Dowling JE (2001) Behavioral screening for cocaine sensitivity in mutagenized zebrafish. Proc Natl Acad Sci USA 98:11691-11696.

DiFranza JR, Lew RA (1995) Effect of maternal cigarette smoking on pregnancy complications and sudden infant death syndrome. J Fam Pract 40:385-394.

Eisen JS, Myers PZ, Westerfield M (1986) Pathway selection by growth cones of identified motoneurones in live zebra fish embryos. Nature 320:269-271.

Fashena D, Westerfield M (1999) Secondary motoneuron axons localize DM-GRASP on their fasciculated segments. J Comp Neurol 406:415-424.

Foreman MB, Eaton RC (1993) The direction change concept for reticulospinal control of goldfish escape. J Neurosci 13:4101-4113. 
Granato M, Nusslein-Volhard C (1996) Fishing for genes controlling development. Curr Opin Genet Dev 6:461-468.

Hale ME, Ritter DA, Fetcho JR (2001) A confocal study of spinal interneurons in living larval zebrafish. J Comp Neurol 437:1-16.

Hanneman E, Westerfield M (1989) Early expression of acetylcholinesterase activity in functionally distinct neurons of the zebrafish. J Comp Neurol 284:350-361.

Higashijima S, Hotta Y, Okamoto H (2000) Visualization of cranial motor neurons in live transgenic zebrafish expressing green fluorescent protein under the control of the islet-1 promoter/enhancer. J Neurosci 20:206-218.

Hory-Lee F, Frank E (1995) The nicotinic blocking agents $d$-tubocurare and $\alpha$-bungarotoxin save motoneurons from naturally occurring death in the absence of neuromuscular blockade. J Neurosci 15:6453-6460.

Kimmel CB, Ballard WW, Kimmel SR, Ullmann B, Schilling TF (1995) Stages of embryonic development of the zebrafish. Dev Dyn 203:253-310.

Kuwada JY, Bernhardt RR, Nguyen N (1990) Development of spinal neurons and tracts in the zebrafish embryo. J Comp Neurol 302:617-628.

Landmesser L (1992) The relationship of intramuscular nerve branching and synaptogenesis to motoneuron survival. J Neurobiol 23:1131-1139.

Liu DW, Westerfield M (1992) Clustering of muscle acetylcholine receptors requires motoneurons in live embryos, but not in cell culture. J Neurosci 12:1859-1866.

Liu KS, Fetcho JR (1999) Laser ablations reveal functional relationships of segmental hindbrain neurons in zebrafish. Neuron 23:325-335.

McIntosh JM, Santos AD, Olivera BM (1999) Conus peptides targeted to specific nicotinic acetylcholine receptor subtypes. Annu Rev Biochem 68:59-88.

Melancon E, Liu DW, Westerfield M, Eisen JS (1997) Pathfinding by identified zebrafish motoneurons in the absence of muscle pioneers. J Neurosci 17:7796-7804.

Muneoka K, Ogawa T, Kamei K, Muraoka S, Tomiyoshi R, Mimura Y, Kato H, Suzuki MR, Takigawa M (1997) Prenatal nicotine exposure affects the development of the central serotonergic system as well as the dopaminergic system in rat offspring: involvement of route of drug administrations. Brain Res Dev Brain Res 102:117-126.

Myers PZ, Eisen JS, Westerfield M (1986) Development and axonal outgrowth of identified motoneurons in the zebrafish. J Neurosci 6:2278-2289

Navarro HA, Seidler FJ, Eylers JP, Baker FE, Dobbins SS, Lappi SE, Slotkin TA (1989) Effects of prenatal nicotine exposure on development of central and peripheral cholinergic neurotransmitter systems: evidence for cholinergic trophic influences in developing brain. J Pharmacol Exp Ther 251:894-900.

Navarro HA, Mills E, Seidler FJ, Baker FE, Lappi SE, Tayyeb MI, Spencer JR, Slotkin TA (1990) Prenatal nicotine exposure impairs $\beta$-adrenergic function: persistent chronotropic subsensitivity despite recovery from deficits in receptor binding. Brain Res Bull 25:233-237.

Olds DL, Henderson Jr CR, Tatelbaum R (1994) Intellectual impair- ment in children of women who smoke cigarettes during pregnancy. Pediatrics [Erratum (1994) 93:973] 93:221-227.

Ono F, Shcherbatko A, Higashijima S, Fetcho J, Mandel G, Brehm P (2001) Paralytic zebrafish lacking ACh receptors fail to localize rapsyn clusters to the synapse. J Neurosci 21:5439-5448.

Oppenheim RW, Prevette D, D'Costa A, Wang S, Houenou LJ, McIntosh JM (2000) Reduction of neuromuscular activity is required for the rescue of motoneurons from naturally occurring cell death by nicotinicblocking agents. J Neurosci 20:6117-6124.

Pike SH, Melancon EF, Eisen JS (1992) Pathfinding by zebrafish motoneurons in the absence of normal pioneer axons. Development 114:825-831.

Pittman R, Oppenheim RW (1979) Cell death of motoneurons in the chick embryo spinal cord. IV. Evidence that a functional neuromuscular interaction is involved in the regulation of naturally occurring cell death and the stabilization of synapses. J Comp Neurol 187:425-446.

Pugh PC, Berg DK (1994) Neuronal acetylcholine receptors that bind $\alpha$-bungarotoxin mediate neurite retraction in a calcium-dependent manner. J Neurosci 14:889-896.

Ribera AB, Nusslein-Volhard C (1998) Zebrafish touch-insensitive mutants reveal an essential role for the developmental regulation of sodium current. J Neurosci 18:9181-9191.

Role LW, Berg DK (1996) Nicotinic receptors in the development and modulation of CNS synapses. Neuron 16:1077-1085.

Saint-Amant L, Drapeau P (1998) Time course of the development of motor behaviors in the zebrafish embryo. J Neurobiol 37:622-632.

Segawa H, Miyashita T, Hirate Y, Higashijima S, Chino N, Uyemura K, Kikuchi Y, Okamoto H (2001) Functional repression of Islet-2 by disruption of complex with Ldb impairs peripheral axonal outgrowth in embryonic zebrafish. Neuron 30:423-436.

Sexton M, Fox NL, Hebel JR (1990) Prenatal exposure to tobacco. II. Effects on cognitive functioning at age three. Int J Epidemiol 19:72-77.

Smith J, Fauquet M, Ziller C, Le Douarin NM (1979) Acetylcholine synthesis by mesencephalic neural crest cells in the process of migration in vivo. Nature 282:853-855.

Svoboda KR, Linares AE, Ribera AB (2001) Activity regulates programmed cell death of zebrafish Rohon-Beard neurons. Development 128:3511-3520

Ward JM, Cockcroft VB, Lunt GG, Smillie FS, Wonnacott S (1990) Methyllycaconitine: a selective probe for neuronal $\alpha$-bungarotoxin binding sites. FEBS Lett 270:45-48.

Westerfield M (1995) The zebrafish book. Eugene, OR: University of Oregon.

Westerfield M, Liu DW, Kimmel CB, Walker C (1990) Pathfinding and synapse formation in a zebrafish mutant lacking functional acetylcholine receptors. Neuron 4:867-874.

Zheng JQ, Felder M, Connor JA, Poo MM (1994) Turning of nerve growth cones induced by neurotransmitters. Nature 368:140-144.

Zoli M, Le Novere N, Hill Jr JA, Changeux JP (1995) Developmental regulation of nicotinic $\mathrm{ACh}$ receptor subunit mRNAs in the rat central and peripheral nervous systems. J Neurosci 15:1912-1939. 